\title{
The Use of Recombinant Human Bone Morphogenic Protein-2 (rhBMP-2) in Treatment for Cysts of the Oral and Maxillofacial Regions
}

\author{
Jong-Bum Lee, Taek-Woo Kim, Seok-Hwan Ryu, Dong-Yoon Shin, Hyun-Ho Ryu, \\ Seok-Yong Park, Young-Cho Shin, Bok-Joo Kim, Hee-Seong Hwang, Chul-Hoon Kim
}

Division of Oral and Maxillofacial Surgery, Department of Dentistry, Dong-A University Medical Center

\begin{abstract}
The purpose of this study is to report on five cases treated with bone graft using recombinant human bone morphogenetic protein-2 (rhBMP-2) on jaw defects after cyst enucleation. We performed bone graft with BMP (rhBMP- $2+\beta$-tricalcium phosphate/hydroxyapatite) wrapped with a collagen sponge on jaw defects after cyst enucleation. Postoperative panoramic radiographs were taken periodically. After 1 to 12 months, bone remodeling was observed in the jaw defect area. In our cases, there were few signs or symptoms of recurrence of the cyst during the follow-up period.
\end{abstract}

Key words: rhBMP-2, Bone transplantation, Odontogenic cysts

\section{Introduction}

Odontogenic cysts in the oral and maxillofacial region are divided into developmental cysts which have no clear cause for occurrence, and inflammatory cysts associated with the inflammatory process. While periapical cyst, residual cyst, and periodontal cyst, and so on are inflammatory, dentigerous cyst, odontogenic keratocyst, calcifying odontogenic cyst, lateral periodontal cyst, glandular odontogenic cyst, and so on are developmental. Most cysts in the jawbone are odontogenic cysts, and periapical cyst is the most commonly occurring cyst (65\%), followed by dentigerous cyst and odontogenic keratocyst[1-3]. Among them, odontogenic keratocyst and calcifying odontogenic cyst are classified according to benign neoplasms rather than kinds of cysts, due to their high recurrence rate and aggressive properties.

Cyst decompression or cyst enucleation is commonly employed as a treatment for odontogenic cysts.

For cyst enucleation, a bone graft into the bony defects after enucleation is preferred; however, satisfactory healing without a bone graft, depending on the conditions of the cyst, has commonly been observed. The size and location of the cyst, impacted tooth, the amount and state of surrounding bones, soft tissue defect, patient's performance status, preoperative inflammatory condition, and periapical lesion are known to affect healing of cysts.

In general, in the case of a large cyst, it is difficult to

RECEIVED July 29, 2013, REVISED September 23, 2013, ACCEPTED November 8, 2013

Correspondence to Chul-Hoon Kim

Division of Oral and Maxillofacial Surgery, Department of Dentistry, Dong-A University Medical Center

26 Daesingongwon-ro, Seo-gu, Busan 602-715, Korea

Tel: 82-51-240-5475, Fax: 82-51-241-5475, E-mail: bbp2000@hanmail.net

(c) This is an open access article distributed under the terms of the Creative Commons Attribution Non-Commercial License (http://creativecommons.org/licenses/ by-nc/3.0) which permits unrestricted non-commercial use, distribution, and reproduction in any medium, provided the original work is properly cited. 
anticipate spontaneous healing. For this reason, a bone graft is preferred, however, an additional operation is required at donor sites, or additional expenses are incurred for bone substitute. Above all, when complications such as infection arise after the operation, an operation for removal of bone graft material should be performed. Thus, it can be said that a bone graft is not always necessary, if a clinically favorable outcome can be obtained with only cyst enucleation.

Whether or not the bone graft will have to be performed depends on surgeon's preference and an evidence-based standard treatment protocol has not been established. In this case report, we performed a bone graft using recombinant human bone morphogenetic protein-2 (rhBMP-2) in the bony defect left after cyst enucleation for a patient who visited our hospital for cysts in the oral and maxillofacial region, compared with the radiologic healing aspect after one month to one year of follow-up observation, and investigated the presence of complications in order to evaluate the effectiveness of bone graft after cyst enucleation.

\section{Case Report}

For five patients (three males and two females), cyst enucleation and rhBMP-2 loaded bone graft were implemented under general anesthesia, and they were monitored for one to twelve months after the operation (Table 1, Fig. 1 5).

Under general anesthesia, the lesion was removed and apicoectomy was performed after extraction of the associated tooth, and biopsy of the removed tissue was performed. Following enucleation, 0.25 to $0.5 \mathrm{~g}$ of BMP (rhBMP-2+ $\beta$-tricalcium phosphate $[\beta$-TCP]/hydroxyapatite [HA]); Cowellmedi, Seoul, Korea) wrapped with a collagen sponge (Teruplug; Olympus Terumo Biomaterials, Tokyo,

Table 1. Summary of cases

\begin{tabular}{|c|c|c|c|c|c|}
\hline & Case 1 & Case 2 & Case 3 & Case 4 & Case 5 \\
\hline Age (yr) & 53 & 25 & 60 & 24 & 70 \\
\hline Sex & Female & Male & Male & Female & Male \\
\hline $\begin{array}{l}\text { Symptom and } \\
\text { duration }\end{array}$ & $\begin{array}{l}\text { Pain and paresthesia in } \\
\text { left side of her face oc- } \\
\text { curred since a month } \\
\text { before the visit }\end{array}$ & $\begin{array}{l}\text { Pain in mandibular right } \\
\text { region occurred since } \\
\text { a week before the visit }\end{array}$ & $\begin{array}{l}\text { Halitosis and pain in } \\
\text { mandibular posterior } \\
\text { region occurred since } \\
\text { a month before the } \\
\text { visit }\end{array}$ & $\begin{array}{l}\text { Pain in right side of her } \\
\text { face occurred since } 3 \\
\text { days before the visit }\end{array}$ & $\begin{array}{l}\text { Gingival enlargement in } \\
\text { labial surface of man- } \\
\text { dibular anterior region } \\
\text { occurred since } 4 \text { days } \\
\text { before the visit }\end{array}$ \\
\hline Diagnosis & $\begin{array}{l}\text { Inflammatory } \\
\text { dentigerous cysts }\end{array}$ & Dentigerous cyst & Dentigerous cyst & Dentigerous cyst & Radicular cyst \\
\hline $\begin{array}{l}\text { Graft amount of } \\
\text { BMP (g) }\end{array}$ & 0.25 & 0.25 & 0.5 & 0.25 & 0.25 \\
\hline Systemic disease & None & None & None & None & None \\
\hline Follow-up period & 11 months & 1 year & 1 year & 7 months & 1 month \\
\hline Complication & None & None & Paresthesia of lower lip & Mild edema & None \\
\hline
\end{tabular}

BMP, bone morphogenetic protein.
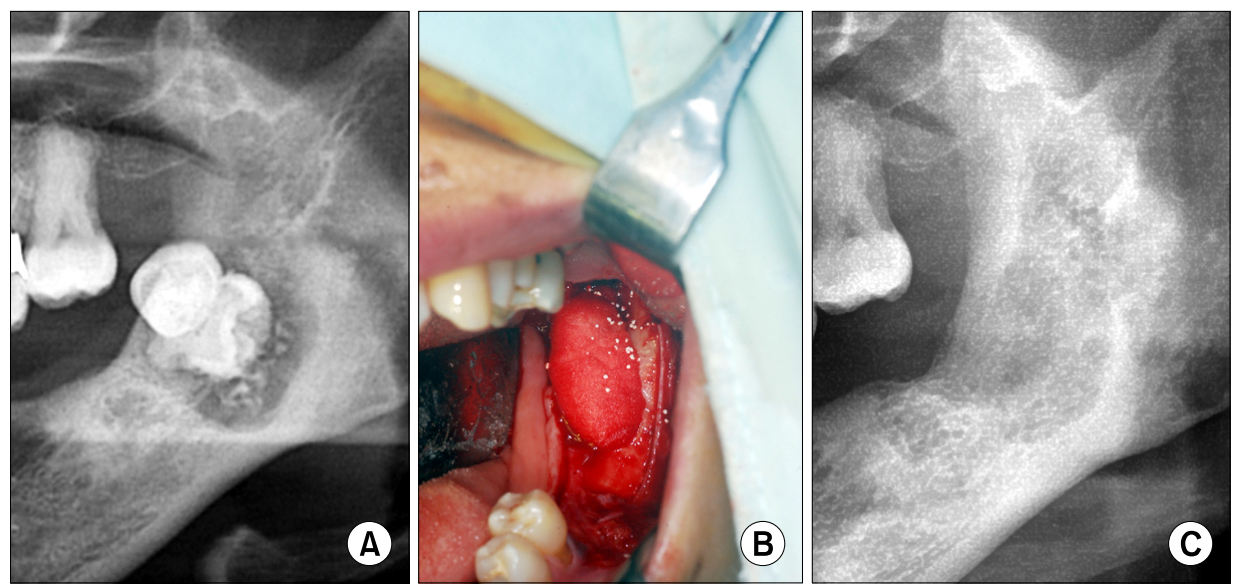

Fig. 1. Case 1 (53-year-old female). (A) Pre-operative panoramic radiogram. (B) Bone graft (recombinant human bone morphogenetic protein- $2+\beta$ tricalcium phosphate/hydroxyapatite). (C) Post-operative panoramic radiogram after 11 months. 

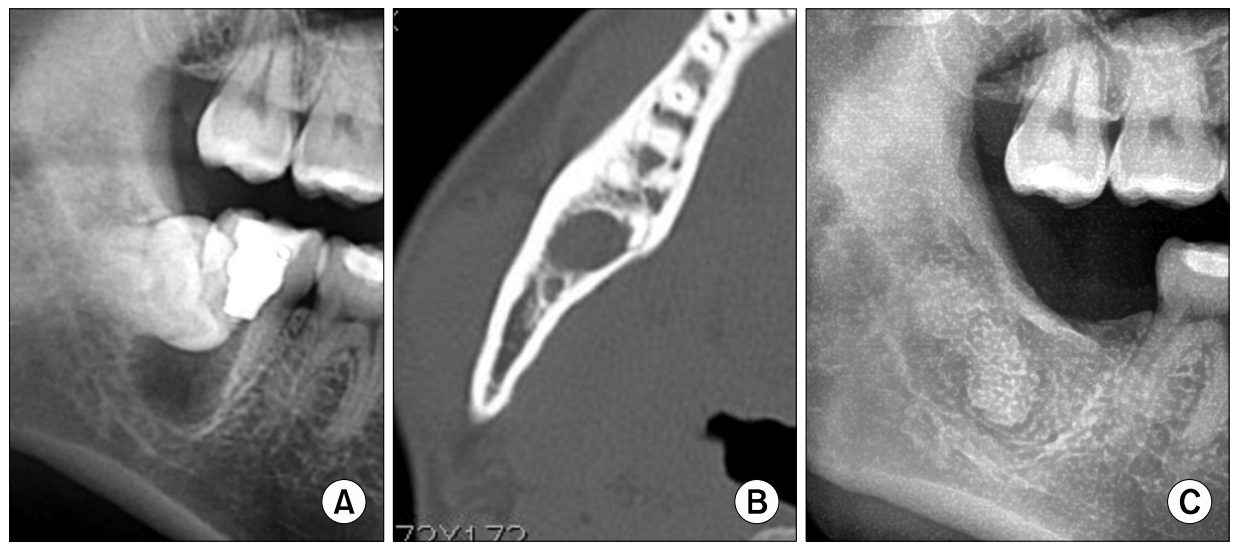

Fig. 2. Case 2 (25-year-old male). (A) Pre-operative panoramic radiogram. (B) Pre-operative computred tomography image. (C) Post-operative panoramic radiogram after one year.
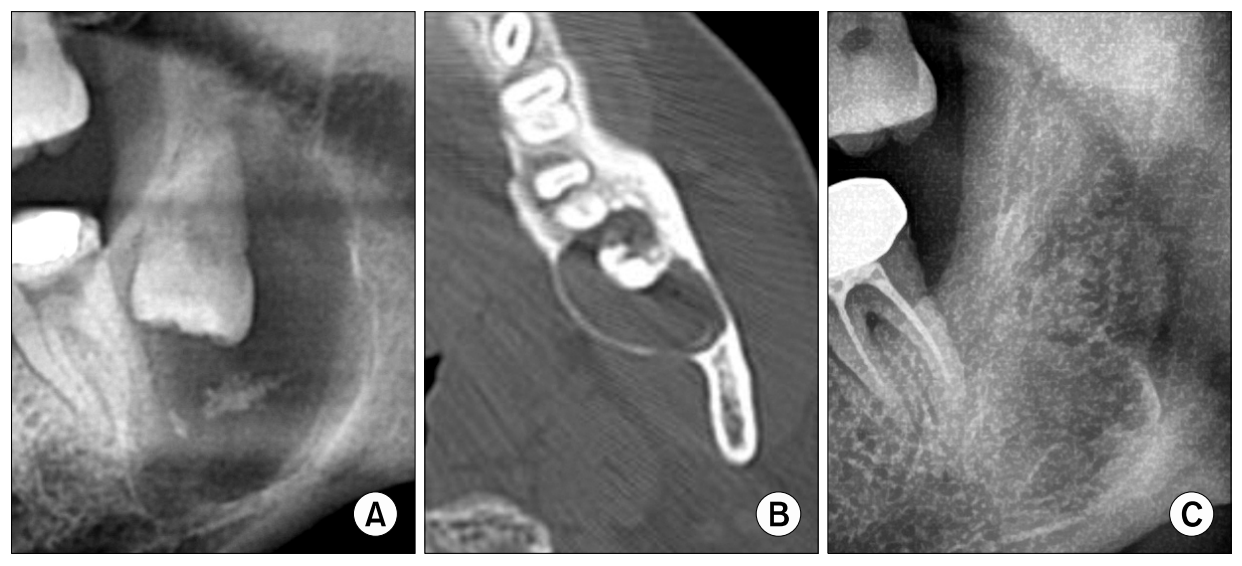

Fig. 3. Case 3 (60-year-old male). (A) Pre-operative panoramic radiogram. (B) Pre-operative computred tomography image. (C) Post-operative panoramic radiogram after one year.
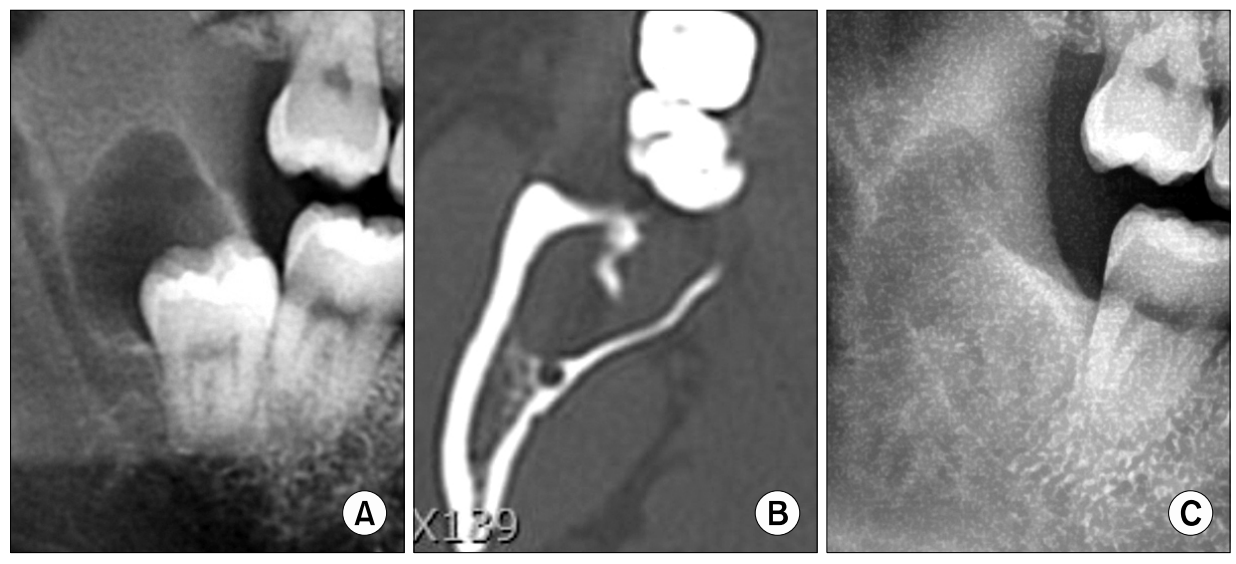

Fig. 4. Case 4 (24-year-old female). (A) Pre-operative panoramic radiogram. (B) Pre-operative computred tomography image. (C) Post-operative panoramic radiogram after seven months.

Japan) was transplanted into the bony defects.

Although differences were observed among individual cases during the follow-up period after enucleation, satisfactory bone regeneration was observed in the bone defects, and recurrence of the cyst and other complications were not found during follow-up monitoring, except for slight paresthesia (one patient) and edema (one patient).

A summary of the details of each case is shown in Table 1.

\section{Discussion}

Cyst enucleation leads to development of defects in the jawbone, and, in this case, a bone graft may be planned in order to improve healing of the bone defects. A bone graft after cyst enucleation is preferred by some surgeons, as it is favorable to bone regeneration and decreases the possibility that even spontaneous healing occurs, it is not 

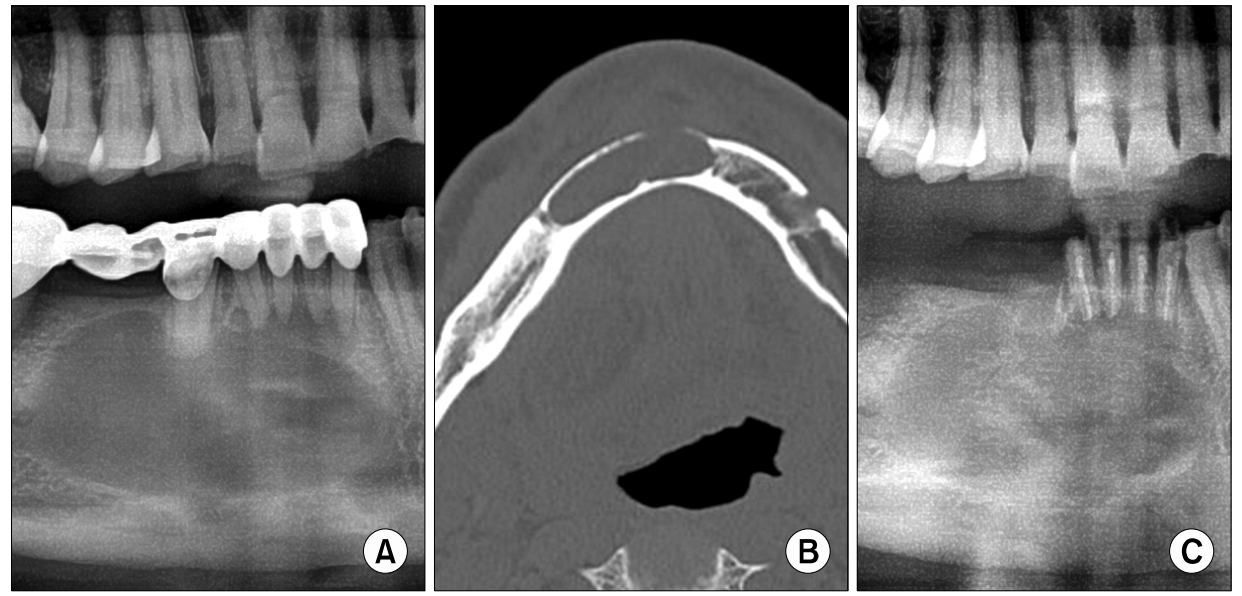

Fig. 5. Case 5 (70-year-old male). (A) Pre-operative panoramic radiogram. (B) Pre-operative computred tomography image. (C) Post-operative panoramic radiogram after one month.

perfectly healed but rather healed partially as soft tissues.

In cases of small cysts, it is possible to use a small amount of xenograft or synthetic bone, whereas for a large-sized cyst, an autograft like the ilium is required; thus, there are disadvantages, including the possibility of complications and the need to perform surgery at the donor site. Horowitz and Bodner[4] reported that a bone graft was recommended for promotion of bone regeneration and to enhance the appearance of soft tissues, however, failure has been reported in 20\% of bone graft cases. Numerous cases involving use of freeze-dried allogenic bone have been reported and complications occurred in approximately $17.6 \%$ to $25.0 \%$ of cases. This means that some surgeons consider a bone graft unnecessary, in that it is possible to remove the cyst without a bone graft and without development of complications, and it could lead to secondary healing, if partial healing of soft tissues does not affect the function and appearance of the jawbone.

However, spontaneous healing is limited in bone defects over a certain size; this is called a critical size defect. This is mainly studied in animal experiments. In particular, it is known that a rabbits' cranium is larger than $15 \mathrm{~mm}[5]$, and bone defects over $8 \mathrm{~mm}$ in the dogs' mandible are known not to show spontaneously healing[6]. In fact, because practical clinical situations are influenced by a large number of factors, it is difficult to determine the critical size defect for humans. In this study, a bone graft using a synthetic bone was combined, because most cysts were over $2 \mathrm{~cm}$, and it was considered that a complete recovery of bony defects with spontaneous healing only was difficult to anticipate.
Materials used for bone graft include autogenous bone graft, allograft, xenograft, and synthograft, and, quite recently, platelet-rich plasma (PRP) and rhBMP-2 have also been used in promotion of osteogenesis[7]. As a synthograft, HA and $\beta$-TCP are used most often, and $\beta$-TCP, an absorptive ceramic particle, is a synthetic biomaterial used frequently as a substrate for bone regeneration and augmentation in the oral and maxillofacial region. Ogose et al.[8] suggested that porous $\beta$-TCP is a biodegradable material with excellent osteoconductivity and clinical efficiency. In addition, the porous structure of $\beta$-TCP plays a role as scaffold for BMP or PRP. Urist[9] discovered BMP while investigating substrates for osteoinduction. As a kind of transforming growth factor $\beta$ group, this protein is preserved in various tissues for a long time, and has multiple functions, such as embryogenesis, homeostasis maintenance, and healing inside the tissue, or while tissues are being generated. According to the studies reported so far, BMP is also a strong inducer of osteogenesis and osteoblasts[10]. In order to promote bone healing, a number of researchers have been making an effort to improve osteoinductive capacity by addition of rhBMP-2 to $\beta$-TCP. After observing bone formation using rhBMP-2 and TCP at various concentrations, Matsushita et al.[11] insisted that rhBMP-2 and $\beta$-TCP have osteoinductive capacity and biodegradable properties. In a comparison of two groups using various ratios of HA and TCP in the rabbits' cranium, Alam et al.[12] also reported that a bone formation was observed in the group with rhBMP-2, whereas a fibrous connective tissue was observed in the control group without rhBMP-2. Jingushi et al.[13] observed bone formation 
when transplanting rhBMP-2 and $\beta$-TCP in rabbits' muscle. BMP used in this research is rhBMP-2, which was freeze-dried on the surface of $\beta$-TCP, and here, $\beta$-ТCP works as a scaffold of rhBMP-2. Use of a collagen sponge along with BMP is thought not only to play a role as a membrane to prevent grown soft tissues from coming in contact with rhBMP-2 but also to help to fix a graft material firmly by filling the remaining space of wide bony defects.

A bone graft into bony defects after cyst enucleation relies heavily on surgeons' preferences, and a standard treatment protocol has not been established. Most of the five cases described in this study had wide bony defects greater than $2 \mathrm{~cm}$, and based on the judgment that complete bone formation could not occur with spontaneous healing only, rhBMP-2 ( $\beta$-TCP+HA) was transplanted into them using a collagen carrier, and post-operative follow-up showed satisfactory bone formation in the majority of the patients, regardless of age and gender.

Sufficient effect of bone graft was achieved with a relatively small amount of bone graft materials ( 0.25 to 0.50 $\mathrm{g}$ ), with realistic cystic size when bone graft materials were transplanted using collagen carriers, compared to the method for filling extensive bony defects with only bone graft material. Although many studies have reported that rhBMP-2 showed higher osteoinductive capacity, it is still more expensive than other graft materials, including allografts and xenografts, and this problem requires significant improvement.

In addition, in most cases, bone formation was completed within one year; however, it is difficult to be certain that this indicates significant differences compared to cases in which bone grafts were not performed, and for a more precise evaluation, observation of more cases would be needed in the future.

\section{References}

1. Jones AV, Craig GT, Franklin CD. Range and demographics of odontogenic cysts diagnosed in a UK population over a 30-year period. J Oral Pathol Med 2006;35:500-7.

2. Grossmann SM, Machado VC, Xavier GM, et al. Demographic profile of odontogenic and selected nonodontogenic cysts in a Brazilian population. Oral Surg Oral Med Oral Pathol Oral Radiol Endod 2007;104:e35-41.

3. Tortorici S, Amodio E, Massenti MF, Buzzanca ML, Burruano F, Vitale F. Prevalence and distribution of odontogenic cysts in Sicily: 1986-2005. J Oral Sci 2008;50:15-8.

4. Horowitz I, Bodner L. Use of xenograft bone with aspirated bone marrow for treatment of cystic defect of the jaws. Head Neck 1989;11:516-23.

5. Dodde R 2nd, Yavuzer R, Bier UC, Alkadri A, Jackson IT. Spontaneous bone healing in the rabbit. J Craniofac Surg 2000;11:346-9.

6. Hjorting-Hansen E, Andreasen JO. Incomplete bone healing of experimental cavities in dog mandibles. Br J Oral Surg 1971;9:33-40

7. Schuckert KH, Jopp S, Teoh SH. Mandibular defect reconstruction using three-dimensional polycaprolactone scaffold in combination with platelet-rich plasma and recombinant human bone morphogenetic protein-2: de novo synthesis of bone in a single case. Tissue Eng Part A 2009;15: 493-9.

8. Ogose A, Hotta T, Hatano H, et al. Histological examination of beta-tricalcium phosphate graft in human femur. J Biomed Mater Res 2002;63:601-4.

9. Urist MR. Bone: formation by autoinduction. Science 1965; 150:893-9.

10. Asahina I, Sampath TK, Hauschka PV. Human osteogenic protein-1 induces chondroblastic, osteoblastic, and/or adipocytic differentiation of clonal murine target cells. Exp Cell Res 1996;222:38-47.

11. Matsushita N, Terai H, Okada T, et al. A new bone-inducing biodegradable porous beta-tricalcium phosphate. J Biomed Mater Res A 2004;70:450-8.

12. Alam I, Asahina I, Ohmamiuda K, Enomoto S. Comparative study of biphasic calcium phosphate ceramics impregnated with rhBMP-2 as bone substitutes. J Biomed Mater Res 2001; 54:129-38.

13. Jingushi S, Urabe K, Okazaki K, et al. Intramuscular bone induction by human recombinant bone morphogenetic protein-2 with beta-tricalcium phosphate as a carrier: in vivo bone banking for muscle-pedicle autograft. J Orthop Sci 2002;7:490-4 